changes associated with particular lesion lateralisation or location. However, any hypothesis of the mechanisms of mood disturbance following focal brain injury must account for the apparent association of left anterior lesions with depression and of right-sided lesions with euphoria. It is to be hoped that as our understanding of the subcortical substrates of behaviour increases, we will be able to better understand the pathogenesis of cases such as that reported (McGilchrist et al, 1993).

OKe, A., Keller, R., Mefrord, I., et al (1978) Lateralisation on norepinephrine in human thalamus. Science, 200, 1411-1413.

Starkstein, S. E., Boston, J. D. \& Robinson, R. G. (1988a) Mechanisms of mania after brain injury: 12 case reports and review of the literature. Journal of Nervous and Mental Disease, 176, 87-100.

-, Robinson, R. G., BerthiER, M. L., et al (1988b) Differential mood changes following basal ganglia vs thalamic lesions. Archives of Neurology, 45, 725-730.

ANOOP RANJAN VARMa JOHN MORIARTY

MichaEL, R. TRIMBLE

Raymond Way Neuropsychiatry Research Group

Institute of Neurology

Queen Square

London WCIN $3 B G$

\section{Parental bonding}

SIR: Morris' letter (BJP, July 1993, 163, 127) criticising my paper (BJP, March 1993, 162, 335-344) requires a reply. Bowlby's definition of 'a poor early relationship' in the passage I cited was too general to be incorporated into a testable hypothesis. Since Bowlby went on to refer to the individual's "capacity to make affectional bonds", it seemed that the most precise hypothesis I could test was that there was a relationship between recalling having good affectional bonds in childhood and the ability to make good affectional bonds in adult life. Maternal care was the experience which came closest to having good affectional bonds. In the two samples I used, this was assessed by interview and, in the younger sample, it was also assessed by the care scale of the mother version of Parker's Parental Bonding Instrument (PBI). In an earlier paper (BJP, December 1988, 153, 758-769) I reported upon findings using scales of both the mother and the father versions of the PBI. Focusing specifically upon the care scale is a perfectly legitimate exercise. To be consistent, I also focused specifically upon the affection-given scale of the Marital Patterns Test.

It seems that what Morris is suggesting is that I should extend the study to testing the additional hypothesis that being subjected to parental over- protection in childhood (the other scale of the PBI) predisposes the individual to either seek or avoid overprotection in later relationships, and that I should use the directiveness scale of the self-rating and partner-rating questionnaires (BJP, May 1991, $158,648-657)$ as a measure of such overprotection. This is indeed a reasonable suggestion since Parker quite often (and more correctly I think) refers to the overprotection scale as the control scale, and control and directiveness are comparable constructs. Since, however, in the 1988 paper there was shown to be a highly significant association between recalled maternal overprotection and depression, the intervening variable of depression is going to complicate matters as it did with the maternal care hypothesisan issue which Morris studiously avoids.

Morris refers to "the total parental relationship" as getting closer to Bowlby's hypothesis. In the passage I cited, Bowlby used the term "an individual's experiences with his parents". This is a vague term which can hardly be preferable to defining the recollected relating behaviour of one or other parent in certain specific ways. I end my paper by maintaining that further progress in this field will depend upon expanding the theoretical base, increasing the range of parameters of relating to be considered, and developing new instruments which are based upon this broader perspective. In my recent book (Birtchnell, 1993) this is what I have tried to do.

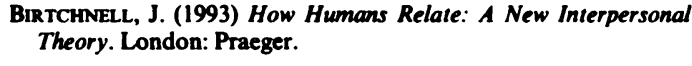

Institute of Psychiatry

JOHN BIRTCHNELL

De Crespigny Park

Denmark Hill

London SE5 8AF

\section{Neural network model of amnesia}

SIR: Neural network modelling is a rapidly advancing area which, if appropriately applied, may be useful in psychiatry. The article by Carrie (BJP, August 1993, $163,217-222)$ is therefore welcomed with enthusiasm. Several comments are, however, important.

A simple associative network is used and the author chooses to represent diffuse cerebral pathology by random deletion of units. It is important to realise that units are substrates for the representation of patterns (during presentation and retrieval), and the memories for the patterns are stored in the synaptic weights between the units (which change before and after learning). Removal of units will naturally affect 'retrieval' due to the lack of a proper platform for the 